\title{
REPENSAR A LITERATURA INFANTIL COM A PERSPECTIVA DA TEORIA RACIAL CRÍTICA: ANÁLISE DO LIVRO AS BONECAS NEGRAS DE LARA ${ }^{1}$
}

\author{
Samantha Schäfer ${ }^{2}$ \\ Universidade Estadual de Ponta Grossa, UEPG, Departamento de Letras, Ponta \\ Grossa, PR, Brasil. \\ Aparecida de Jesus Ferreira (Orientadora) ${ }^{3}$ \\ Universidade Estadual de Ponta Grossa, UEPG, Departamento de Letras, Ponta \\ Grossa, PR, Brasil.
}

Resumo: Este artigo propõe algumas reflexões acerca de identidades sociais no que se refere à questão racial interseccionada com gênero e às formas como são representadas no livro infantil As bonecas negras de Lara. Os teóricos adotados discutem sobre a Teoria Racial Crítica e outros ainda trabalham a literatura infantil a partir da perspectiva racial com intersecção de gênero. Trata-se de uma pesquisa bibliográfica, que tem por objetivo discutir a relevância da Teoria Racial Crítica na educação e trazer a análise de um livro com personagens negras. Como resultado da pesquisa, enfatizo ${ }^{4}$ a importância dessa teoria para desvelar o preconceito racial nas escolas e a revisão das escolhas de Literatura Infantil. Saliento a necessidade do rompimento com os silenciamentos que permeiam o contexto pedagógico em torno das diferenças, problematizando-as e superando-as.

\footnotetext{
${ }^{1}$ Resposta à pergunta: Qual é a importância da Literatura Infantil para uma educação inclusiva, que contemple a questão racial com intersecção em gênero, a partir da análise do livro infantil As bonecas negras de Lara. Esta reflexão foi feita como trabalho final da disciplina de Formação de Professores, Identidade Profissional e Letramento Racial.

${ }^{2}$ Samantha Schäfer - Professora da Secretaria Municipal de Educação de Ponta Grossa. Mestranda em Estudos da Linguagem da UEPG (Universidade Estadual de Ponta Grossa). Orientanda da Prof ${ }^{a}$. Dr ${ }^{a}$. Aparecida de Jesus Ferreira. E-mail: samanthaschafer@hotmail.com ; ORCID: https://orcid.org/0000$\underline{0002-9977-8087}$

${ }^{3}$ Aparecida de Jesus Ferreira, tem doutorado e pós-doutorado pela University of London, Inglaterra. É professora associada da UEPG (Universidade Estadual de Ponta Grossa), atuando na graduação e no programa de mestrado em Estudos da Linguagem, na mesma universidade. E-mail: aparecidadejesusferreira@gmail.com ; ORCID: https://orcid.org/0000-0002-3728-0793

${ }^{4}$ Este artigo está em primeira pessoa porque foi escrito como parte da disciplina, como minha reflexão. A professora da disciplina, Aparecida de Jesus Ferreira, consta como minha orientadora, pois foi quem me orientou e colaborou na escrita durante o processo.
} 
Palavras-chave: Teoria Racial Crítica. Literatura Infantil. Raça e Gênero.

\title{
RETHINKING KIDS' LITERATURE THROUGH CRITICAL RACE THEORY: ANALYSIS OF THE BOOK LARA'S BLACK DOLLS
}

\begin{abstract}
This article proposes to bring some reflections about social identities with regard to the racial issue intersected with gender, and the ways in which these issues are represented in a children's book Lara's black dolls. The theoretical framework adopted for the discussion on Critical Racial Theory and the Theoretical support for the analysis of children's literature worked from a racial perspective From a methodological point of view, this is a bibliographic research, which aims to discuss the relevance of Critical Racial Theory in education and bring an analysis of a book with black characters. As a result of the research, I emphasize the importance of this Theory to unveil racial prejudice in school institutions and to review the choices of Children's Literature. I emphasize the need to break with the silences that permeate the pedagogical context around differences, problematizing them.
\end{abstract}

Keywords: Critical Race Theory. Kids literature. Race. Gender

\section{REPENSAR LA LITERATURA INFANTIL A TRAVÉS DE LA TEORÍA CRÍTICA RACIAL: ANÁLISIS DEL LIBRO MUÑNEAS NEGRAS DE LARA}

Resumen: Este artículo propone traer algunas reflexiones sobre las identidades sociales con respecto al tema racial entrecruzado con el género y las formas en que estos temas están representados en un libro para niños Las muñecas negras de Lara. El referencial teórico adoptado son los autores que discuten la Teoría Racial Crítica y los autores que trabajan en la literatura infantil desde una perspectiva racial con intersección de género. En metodología, esta es una investigación bibliográfica, cuyo objetivo es discutir la relevancia de Teoría Racial Crítica en la educación y traer un análisis de un libro con personajes negros. Como resultado de la investigación, enfatizo la importancia de esta teoría para quitar el velo de los prejuicios en las escuelas y revisar las opciones de Literatura Infantil. Insisto en la necesidad de romper con los silencios que impregnan el contexto pedagógico en torno a las diferencias, problematizándolas.

Palabras clave: Teoría racial crítica. Literatura infantil. Raza y género

\section{REPENSER LA LITTÉRATURE ENFANTINE À TRAVERS LA THÉORIE RACIALE CRITIQUE: ANALYSE DU LIVRE LES POUPÉES NOIRES DE LARA}

Résumé: Cet article propose d'apporter quelques réflexions sur les identités sociales concernant la question raciale croisée avec le genre social, et la manière dont ces questions sont représentées dans un livre pour les enfants "Les poupées noires de Lara". Le cadre théorique adopté est constitué des auteurs qui discutent de la théorie raciale critique et des auteurs qui travaillent sur la littérature jeunesse dans une perspective raciale avec intersection des genres. La méthodologie consiste à une recherche bibliographique qui vise à discuter de la pertinence de la Théorie Critique Raciale dans l'éducation et à apporter une analyse d'un livre avec des personnages noirs. Comme

Revista da ABPN • v. 13 , n. $38 \cdot 2021 \cdot$ p. $3-21$ 
résultats de la recherche, je souligne l'importance de cette théorie pour dévoiler lês préjugés raciaux dans les écoles et revoir les choix littéraires des enfants. J'insiste sur la nécessité de rompre avec les silences qui imprègnent le contexte pédagogique autour des différences, en les problématisant.

Mots clés: Théorie critique raciale. Littérature pour enfants. Race et genre social.

\section{INTRODUÇÃO}

O interesse em analisar o livro infantil As Bonecas Negras de Lara é decorrente do meu trabalho com o Letramento Racial Crítico, que são reflexões feitas no contexto brasileiro por Aparecida de Jesus Ferreira (2014), o qual desenvolvo com meus alunos em uma escola municipal, a partir da experiência com alunos de seis anos, negros e negras, que ao ingressar na escola já apresentam uma identidade não positivada da raça a qual pertencem, sendo este, portanto, um dos motivos que impulsionou minha entrada no mestrado com participação na disciplina "Formação de Professores de Línguas, Identidade Profissional e Letramento Racial", ministrada pela professora Dra. Aparecida de Jesus Ferreira, realizada no primeiro semestre do ano de 2019, nas dependências da Universidade Estadual de Ponta Grossa (UEPG), no Campus Central. Identifiquei-me com a disciplina por ser professora alfabetizadora que utiliza diariamente a Literatura Infantil com personagens negras, e que me oportunizou momentos de aprendizado, de reflexão crítica sobre minha prática pedagógica docente.

Dentro da minha práxis, acordando com Freire (2004), observei a importância da problematização, pelo professor, dos casos de discriminação racial entre as crianças, de modo a solucioná-las no momento em que elas ocorrem, pois à medida que o professor silencia, ele compactua com esses comportamentos discriminatórios, o que poderá causar danos irreparáveis a aprendizagem e socialização dessas crianças. Essa pesquisa insere-se na Linguística Aplicada, a qual segundo Moita Lopes “[...] tem como objetivo fundamental a problematização da vida social, na intenção de compreender as práticas sociais nas quais a linguagem tem papel crucial" (LOPES, 2006, p. 102). Então, pontuo a necessidade de docentes refletirem suas práxis em relação às identidades raciais.

Nesse sentido, a pesquisa sobre a Teoria Racial Crítica está ancorada em estudos desenvolvidos na Educação e Linguística Aplicada, na qual utilizei alguns autores 
pesquisadores da área, tais como: Cardoso e Muller (2018); Cavalleiro (1998); Harris (1993); Ladson-Billings (2001); Rosemberg (1985); Ferreira (2014); Moita Lopes (2006).

Sendo assim, compreendo que a literatura infantil representa uma considerável perspectiva para o desenvolvimento da competência leitora na escola de ensino fundamental inicial da educação básica, pois possibilita ao aluno experiências culturais, estéticas e de identidade, capaz de expor os mais variados assuntos, como contextos pertinentes à diversidade e questões sociais. Porém, a literatura infantil, em relação à cultura afro-brasileira, ainda possui uma grande lacuna a ser preenchida em sala de aula, estando ambas em um constante processo de diálogo e reconstrução. E no que se refere aos estudos das contribuições da literatura infantil, com personagens negras inseridas nas práticas pedagógicas docentes, o apoio teórico teve como base estudos desenvolvidos tanto na área da Linguística Aplicada como da Linguagem e Educação, nas obras dos autores: Castillo (2004); Cavalleiro (2004); Evaristo (2009); Ferreira (2014); Hall (2006); Jovchelovitch (1998); Louro (1997; 2000); nas Diretrizes Curriculares Nacionais para a Educação das Relações Étnico-Raciais e para o Ensino de História e Cultura Afro-brasileira e Africana (2005); Proença Filho (2004).

Nesta ótica, o presente trabalho objetiva apresentar a análise da uma obra de literatura afro-brasileira para os anos iniciais, a partir da Teoria Racial Crítica, evidenciando sua importância para a formação de leitores com consciência étnico-racial, através do livro As bonecas negras de Lara. Compartilho da ideia de que a leitura literária e as questões étnico-raciais necessitam dialogar através de uma apreciação lúdica e construtiva, que favoreça a ótica das diferenças e a valorização das identidades e dessa forma poderá contribuir com a desconstrução do racismo nas escolas. Tentarei responder as seguintes questões: De que forma a Teoria Racial Crítica pode influenciar na área da educação de ensino fundamental inicial na educação básica? Qual é a importância da Literatura Infantil para a realização de uma educação inclusiva que contemple a questão racial com intersecção em gênero de ensino fundamental inicial da educação básica?

Para o melhor desenvolvimento desse trabalho, o artigo foi dividido em duas seções. Na primeira apresento um histórico da Teoria Racial Crítica relacionada com os reflexos do colonialismo brasileiro. E na segunda analiso o livro As bonecas negras de 
Lara, ressaltando os impactos, influências e contribuições que o livro estudado pode proporcionar aos docentes e às crianças no dia a dia escolar em relação à questão racial, além das possíveis problematizações de questões de discriminações cotidianas que, em parte passam despercebidas. Nas considerações finais respondo as perguntas de pesquisa e trago sugestões de pesquisas futuras.

\section{A RELEVÂNCIA DA TEORIA RACIAL CRÍTICA RELACIONADA AO CONTEXTO BRASILEIRO}

Compreendo que a prática de discriminação racial que faz parte da sociedade, se perpetua em grande escala no ambiente escolar. E que essa prática ocorre ao se eleger um padrão como "normal" e ainda, a falta de conhecimento sobre o outro, principalmente, sobre o outro que é diferente.

Normalizar significa eleger - arbitrariamente - uma identidade específica como parâmetro, em relação a qual outras identidades são avaliadas e hierarquizadas. Normalizar significa atribuir a essa identidade todas as características positivas possíveis, em relação às quais todas as outras identidades só podem ser avaliadas de forma negativa à identidade normal e "natural", desejável e única (SILVA, 2000, p. 83).

Desse modo, trago a Teoria Racial Crítica que de acordo com Ladson-Billings (2001), surge da área do Direito nos EUA, pois lá o Direito é baseado em casos que já ocorreram (jurisprudência) ${ }^{5}$. Quando surge um caso novo na corte, ao invés de simplesmente tratá-la como esta "é a história", dentro da Teoria Racial Crítica vê-se que há outra história a ser contada, isto é, essa teoria vem como resposta às limitações da lei, ao tratar de compensar a desigualdade social, oferece um questionamento do Direito tradicional. O que a Teoria Racial Crítica diz: "Há outra história a ser contada". Ela baseia-se fortemente na recuperação da história e da memória em oposição ao

\footnotetext{
${ }^{5}$ Jurisprudência é um termo jurídico que significa o conjunto das decisões, aplicações e interpretações das leis. A jurisprudência pode ser entendida de três formas: como a decisão isolada de um tribunal que não tem mais recursos, pode ser um conjunto de decisões reiteradas dos tribunais ou as súmulas de jurisprudência, que são as orientações resultantes de um conjunto de decisões proferidas com mesmo entendimento sobre determinada matéria. Disponível em: (https://www.tjdft.jus.br/institucional/imprensa/campanhas-e-produtos/direito-facil/edicaosemanal/jurisprudencia-X-precedente). Acesso em: 12 jul. 2021.
} 
tradicional, empíricos e estéreis "Estes são os fatos" (LADSON-BILLINGS, 2001, p. 277).

O uso da Teoria Racial Crítica pode servir como uma lente para ilustrar como novos entendimentos sobre ensinar e aprender são possibilitados, quando velhos paradigmas são rompidos e novos modelos de pesquisa surgem e são colocados em ação na prática docente. Quando indagada na entrevista concedida, sobre as premissas da Teoria Racial Crítica e a importância de se incorporá-la às teorias e práticas educacionais, Ladson-Billings (2001) discorre sobre a experiência americana que, no entanto, aplica-se também ao contexto brasileiro:

O que tentamos fazer no campo da educação foi a partir da perspectiva de que raça é importante, mesmo que pouco teorizada, direitos de propriedade são, por assim dizer, o que sustentam a sociedade e, portanto, a intersecção entre raça e propriedade oferece um interessante objeto de estudo. Passamos a nos interessar por temas ligados à educação escolar. Se olharmos, por exemplo, para o currículo, ele é 'racializado' mas também é uma propriedade intelectual. Nas escolas pobres que atendem crianças não brancas a qualidade da propriedade intelectual é inferior a das crianças brancas de escolas de classe média. $\mathrm{O}$ financiamento é diferente. A própria infraestrutura oferecida às crianças das comunidades empobrecidas está em condições precárias. A metodologia é diferente. Nas escolas que atendem crianças pobres, negras e de outras minorias raciais, encontra-se um tipo de ensino 'de cima para baixo', muito autoritário, que apenas reforça o baixo status dessas crianças. Esse tipo de educação não constitui um empreendimento intelectual; procura-se manter o corpo dessas crianças sob controle, mantê-las quietas na sua carteira sem fazer perguntas, não criticando o sistema e apenas fazendo o que se ordena (LADSON-BILLINGS, 2001, p. 277).

Para Street (2006) era comum nas ciências sociais, até recentemente, encarar a sociedade como, antes de qualquer coisa, um processo de dominação de cima para baixo, com a ideologia servindo os propósitos de um grupo dominante e o resto como vítimas passivas ou relutantes. No Brasil, fazendo uma correlação epistêmica no plano simbólico, os espaços de poder foram ocupados essencialmente por pessoas brancas. Desde a invasão dos colonizadores, os brancos se colocaram na historiografia como superiores, até mesmo na imposição de quais pessoas trabalhariam nesses espaços, instituindo valores cristãos, linguagem e colocando-se como precursores da nova civilização. Séculos depois, os filhos desses recém chegados estudaram na Europa e mantiveram a herança e uma formação intelectual e cultural do povo brasileiro. 
Sendo assim, no decorrer do tempo, o símbolo da identidade racial foi branco. Os "outros", de culturas distintas, que se interpenetraram nos sistemas sociais locais nacionais não foram concordantes ou indicaram igualdade racial, antes foram impostos. O sistema legal protege os interesses dos ocupantes da esfera dominante e ainda possibilita por meio das relações de poder estruturados por meio da linguagem e no acesso a bens materiais e simbólicos o privilégio de uma maioria de brancos (APPLE, 2002).

Dessa forma, o que Ladson-Billings (2001) menciona pode ser usado também no contexto brasileiro, pois a teoria abre um importante caminho no sentido de tornar as estruturas de privilégio raciais visíveis e proporcionar aos docentes oportunidades de refletir sobre suas percepções e experiências de raça.

Sendo assim, a Teoria Racial Crítica pode tornar evidentes esses padrões culturais e raciais sistêmicos que operam nas escolas. Para desvelar ainda mais essa teoria, coloco a disposição dois pontos fundamentais para entendê-la que são: Branquidade, como propriedade, cujos estudos se destacam na década de 1990 nos Estados Unidos, denominado Critical Whiteness Studies, traduzido como Estudos Críticos da Branquidade. Para Moreira, (2014, p. 75) “[...] a literatura norte-americana aponta para a uma teoria que se propõe a discutir, a grosso modo, o lugar de vantagem estrutural ocupado pelo branco nas sociedades que são estruturadas pela dominação racial".

Nesse sentido, Harris (1993) propõe as funções dessa propriedade em três níveis: o direito de possuir, o direito de usar e o direito de dispor. Esses atributos têm servido historicamente para estabelecer a Branquidade como uma forma de propriedade e o segundo ponto, a persistência de não ver cor (colorblind). Há um discurso dominante que se apoia no discurso de não ver cor como um ideal, e para a Teoria Racial Crítica essa é uma escolha política particular que ignora os contextos históricos e sociais em que a raça influenciou e continua influenciar, pois nesse viés se ignora as questões de raça com o suporte na meritocracia, fazendo com que as instituições contribuam na manutenção das desigualdades raciais.

Essas reflexões para a educação infantil são de extrema relevância, pois considerar o pertencimento étnico-racial de crianças é relevante para que a autoestima da criança negra, principalmente, possa ser elevada no contexto escolar. Gomes (2002) 
reflete sobre o discurso pedagógico que privilegia a questão racial, afirmando que esse discurso:

[...] não gira somente em torno de conceitos, disciplinas e saberes escolares. Fala sobre o negro na sua totalidade refere-se ao seu pertencimento étnico, à sua condição socioeconômica, à sua cultura, ao seu grupo geracional, aos valores de gênero etc (GOMES, 2002, p. 43).

Desse modo, fica evidente a importância de superar a branquidade dentro das práticas escolares e do nosso currículo escolar. Uma grande aliada poderia ser a literatura infantil que contenham personagens negras (os) protagonistas. Gomes (2002) relata sobre um discurso de estereótipos e preconceitos sobre o corpo negro que é reproduzido, questionando sobre esses discursos: "Será que eles são superados?" (GOMES, 2002, p. 43).

A qualidade literária dos livros destinados a infância foi se especializando e teve muita influência dos planos nacionais de aquisição de livros infantis. Dentre todos, o suspenso Programa Nacional Biblioteca da Escola (PNBE), quando estava a operar, influenciou por meio das exigências dos editais à especialização da literatura infantil. Durante anos, ele teve como objetivo atender às escolas de ensino público federal, estadual, municipal e do Distrito Federal em todos os âmbitos da educação básica, como também materiais de apoio e referenciais para os profissionais, desde que cadastradas no INEP.

Porém, há uma tensão política e ideológica que impacta os livros no Brasil. Por um lado, há a suspensão de uma política de livros literários, e por outro, a branquidade impera como estruturante nos discursos produzidos e influenciam as infâncias escolarizadas, discriminando brancos e não brancos, a fortalecer, por vezes, desigualdades e assimetrias sociais. Fúlvia Rosemberg (1985), desde a década de setenta, pesquisava sobre os espaços de poder entre adultos e crianças, na confecção dos livros de literatura infantil. Segundo ela, "O livro, nesta perspectiva, é visto como um dos inúmeros agentes do processo de socialização e a mensagem que contém assumem a função de ensinamento real ou virtual" (ROSEMBERG, 1985, p.18). A reflexão crítica da autora ainda nos remete a crítica aos estereótipos, ao racismo e à representação de uma maioria de personagens brancas como norma de humanidade. 
Diante disso, consideramos que a representação discursiva e imagética de personagens não brancas, como proposta na literatura infantil, não é uma forma de pedagogizar o conhecimento, mas, sim, de apresentar uma parcela de crianças sendo crianças nas histórias infantis, descobrindo-se, brincando em um imaginário ficcional ampliado com outros tons de pele. A dor de ser negro e discriminado é algo que se carrega por toda a vida e as crianças negras precisam enfrentar essa situação diariamente. A sub-representação entre as personagens negras foi apontada no trabalho de Cavalleiro (1998), a qual reiterava a tese da hierarquização da categoria branca como padrão de humanidade como segue abaixo:

[...] a disparidade nas representações de personagens negras e brancas pode ser fonte de rebaixamento de autoestima e um facilitador para a construção de autoconceito negativo por parte de crianças negras. E, diametralmente, que pode ser fonte de construção de um sentimento de superioridade por parte das crianças brancas, pelo fato de terem pele branca e fazerem parte, portanto, do grupo que constitui maioria em ilustrações e referências culturais e histórias nesse tipo de material [...] (CAVALLEIRO, 1998, p. 83).

Desta forma, Cavalleiro (1998) destaca como fatores recorrentes nas representações das personagens na literatura infantil: a invisibilidade, o silenciamento, a estereotipia, na qual acabam por estigmatizar e manterem o preconceito e o racismo por meio dos artefatos culturais, em consonância com os estudos apresentados. Rosemberg (1985) afirmava que a estrutura de privilégios da branquidade ainda é compreendida como padrão universal e norma de humanidade.

\section{AS BONECAS NEGRAS DE LARA}

O ensino da história e da cultura afro-brasileira já faz parte da Proposta Nacional de Implementação das Diretrizes Curriculares Nacionais de Educação das Relações Étnico-raciais e para o Ensino de História e Cultura Afro-brasileira e Africana, através da Lei $\mathrm{n}^{\circ} 10.639 / 2003$, da qual se destaca o seguinte objetivo geral:

Promover a valorização e o reconhecimento da diversidade étnico racial na educação brasileira a partir do enfrentamento estratégico de culturas e práticas discriminatórias e racistas institucionalizadas presentes no cotidiano das escolas e nos sistemas de ensino que excluem e penalizam crianças, jovens e adultos 
negros e comprometem a garantia do direito à educação de qualidade de todos e todas (BRASIL, 2003, p. 11).

Apesar desse avanço enquanto marco legal, a educação para as questões étnicoraciais depara-se continuamente com grandes desafios para sua efetivação. Por vezes, a temática é abordada na escola somente em datas isoladas, ou com atividades explorando simplesmente os aspectos formais do texto, sem investir em uma discussão sobre os contextos socioculturais que um assunto dessa natureza implica. Na pesquisa feita por Gonçalves e Silva (2018), onde foram revisados 38 artigos, sete teses e 51 dissertações da área de educação publicadas entre 2003 e 2014, e que tratam do tema educação das relações étnico-raciais em instituições educacionais, a autora afirma "[...] que a escola é um espaço em que os valores eurocêntricos são difundidos e privilegiados, em detrimentos de outras culturas, notadamente, as culturas afro-brasileira e indígena, relegadas a segundo plano, quando não omitidas" (GONÇALVES e SILVA, 2018, p. $123)$.

É, pois, em postura contrária a essas práticas ausentes de significados que o referido estudo argumenta, propondo repensar esses trajetos e promover novas leituras acerca da cultura afro-brasileira, considerando a importância desse assunto como eixo central para se construir uma política afirmativa da diversidade na escola.

E dentro dessa proposta, situa-se a literatura infantil como uma perspectiva relevante para tentar superar esses abismos pertinentes às questões étnico-raciais no ambiente escolar. Como objetivo maior desse estudo, proponho: refletir acerca de identidades sociais no que se refere à questão racial interseccionada com gênero, e às formas como essas questões são representadas no livro infantil escolhido.

As escolas têm oferecido aos seus alunos livros de literatura que legitimam a branquitude como normalidade. Tendo em vista uma mudança de paradigma, a escola pode contribuir na adoção de uma variedade de livros de literatura infantil que contemplem personagens negros não estereotipados, para utilizá-los constantemente. Estereótipos são, muitas vezes, criados e reforçados dentro da própria escola. Para Gomes (2002):

O discurso pedagógico proferido sobre o negro, mesmo sem referir-se explicitamente ao corpo, aborda e expressa impressões e representações sobre esse corpo. O cabelo tem sido um dos principais símbolos utilizados nesse processo, pois desde a escravidão tem sido usado como um dos elementos 
definidores do lugar do sujeito dentro do sistema de classificação racial brasileiro (GOMES, 2002, p. 43)

Cavalleiro (1998) construiu as seguintes hipóteses, ao pesquisar sobre os indivíduos no convívio social relacionado a questões multiétnicas: a dificuldade para professoras de pré-escola perceber problemas em relação às crianças de grupos étnicos diferentes, pois as crianças dessa fase já interiorizaram ideias preconceituosas em relação à raça negra. A partir desses pontos, fiz uma análise das questões mais pertinentes do livro As bonecas negras de Lara relacionadas à questão racial, com intersecção a gênero e ainda outras questões pertinentes.

O livro escolhido foi As Bonecas Negras de Lara (2017), da professora Aparecida de Jesus Ferreira, com ilustrações de Élio Chaves, possui 36 páginas, da $\mathrm{ABC}$ projetos culturais, que pode ser trabalhado com as crianças de todas as idades. Traz a história de três crianças negras que contam suas experiências, que acontecem na sala de aula com o lápis cor da pele, com os brinquedos variados no parque e com a coleção de bonecas negras. As crianças são retratadas com suas famílias diversas, são mostradas como crianças como quaisquer outras que gostam de contar histórias e brincar, valorizando as diferenças.

O critério utilizado para essa escolha foi devido ao livro contemplar tanto as identidades de raça como também as identidades de gênero, que é o foco do meu trabalho. Para Klein e Passos (2018) a educação e identidade negra são vistas como processos construídos pelos sujeitos sociais no decorrer da história, nas relações sociais e culturais mergulhadas na articulação entre individual e o social, entre o passado e o presente, e são incorporadas, ao mesmo tempo em que incorporam, à dinâmica do particular e do universal.

Sendo assim, as relações entre alunos e professores podem contribuir de forma efetiva para uma educação antirracista. Portanto, compete aos professores e a escola desenvolver propostas pedagógicas e metodologia que atendam às necessidades específicas em relação à apropriação do ensino da história e da cultura afro-brasileira, africana e indígena numa perspectiva transdisciplinar, via Letramento Racial Crítico (FERREIRA, 2014) mediado pela Literatura.

\subsection{QUESTÃO RACIAL}


Hall (2003, p. 346) contribui de forma consistente sobre a questão racial ao dizer que “[...] é para a diversidade e não para a homogeneidade da experiência negra que devemos dirigir integralmente a nossa atenção criativa". Infelizmente, nos livros infantis utilizados nos anos iniciais do ensino fundamental básico, os (as) personagens negros (as) têm pouca participação e quando aparecem não são em situações de destaque.

A literatura infantil que os alunos leem nas escolas com maior frequência, raramente mostra famílias negras felizes e bem-sucedidas, ou personagens negras bem vestidas; raramente há príncipes, reis, rainhas de cor negra, assim como também não é comum ver um negro na capa de um livro, ou sendo o personagem principal. Do ponto de vista educativo, esse processo pode estar comprometendo tanto a formação da criança negra quanto da branca. Para a criança branca, essas obras literárias podem reforçar a ideologia da superioridade e supremacia de sua "raça"; por outro lado, pode subestimar, estigmatizar e em muitos casos fragmentar a autoestima da criança negra. (CASTILLO, 2004, p.7).

Para tanto, nesta seção exponho as questões que o livro As Bonecas Negras de Lara trazem relacionadas às reflexões acerca de raça. Para Proença Filho (2004), a literatura brasileira apresenta dois tratamentos em relação ao negro. O primeiro é "a condição negra como objeto, numa visão distanciada" e o segundo "o negro como sujeito, numa atitude compromissada, gerando a literatura sobre o negro, de um lado, e literatura do negro, de outro" (PROENÇA FILHO, 2004, p. 161).

Tendo em vista essas questões já mencionadas, emerge a necessidade de se exigir uma determinada representação em nossas salas de aula da literatura negra, pois assim se reafirma como legítima em toda comunidade. Não é apenas engajamento, é compromisso com a literatura negro-africana, que recusa o estabelecimento pelo outro e reivindica a autoria na representação da identidade étnica- racial.

Lara, ao recorrer às narrativas autobiográficas, traz à tona a sua ancestralidade, com o fato de sua bisavó estar evidenciada nesse momento, o que traduz a importância das pessoas mais velhas, com mais experiências, que retratam e resgata a oralidade africana, levantando assim a questão da necessidade da valorização das questões culturais de um povo e o orgulho de pertencimento à determinada etnia. Trata-se, portanto, de uma representação que articula a identidade da comunidade para ela mesma, já que, como argumenta Evaristo (2009, p. 21), "quando falamos de sujeito na 
literatura negra, não estamos falando de um sujeito particular, de um sujeito construído segundo uma visão romântico-burguesa, mas de um sujeito que está abraçado ao coletivo".

A personagem principal, já é vista na capa do livro, bem vestida e satisfeita por estar com suas bonecas negras na mão. Dessa forma, vejo nitidamente no livro em questão, o protagonismo de Lara, uma menina negra, que se apresenta como uma menina feliz, atuante em seu contexto de vida, que recebe regularmente seus amigos em casa, amigos esses que se alegram em brincar com sua coleção de bonecas negras.

Cabe ao (a) professor (a) a mediação, através de uma análise crítica, selecionar quais os livros realmente contemplam toda a diversidade dos alunos, tornando sua aula democrática e inclusiva, em que todos tenham reais chances de múltiplas aprendizagens, pois conforme enfatiza (CASTILLO, 2004, p. 10):

É importante ressaltar que não se trata de propagar dois tipos de literaturas para públicos distintos. Ou que se deve substituir, em sala de aula, uma literatura pela outra. Mas a preocupação que se deve ter está na necessidade de incorporar outras perspectivas de leituras que rompam com os silenciamentos $\mathrm{e}$ preconceitos raciais existentes nas literaturas tradicionais. E, por outro lado, necessário se faz estabelecer uma postura crítica ao selecionar e ministrar leituras em sala de aula.

Enfim, destaca-se a personagem Paula, a última a contar sua história, que trata de uma questão fundamental aos professores da educação infantil e das séries iniciais do ensino fundamental básico. Ela contou que sua professora levou para sala de aula um boneco e uma boneca, desenhados em um papel, sem cor e sem cabelos. Os alunos deveriam fazer seus autorretratos e achar as suas próprias cores para colorir. Essa atividade pode desmistificar o padrão do lápis salmão, que é muito utilizado para representar a cor da pele. Segundo Ferreira (2014, pp. 249-250) "Para termos uma sociedade mais justa e igualitária, temos que mobilizar todas as identidades de raça branca e negra para refletir sobre raça e racismo e fazer um trabalho crítico no contexto escolar".

Ao professor que tem um olhar atento e compreende a linguagem como produtora de significados, sabe que quando o (a) aluno (a) fala, por exemplo, "Me passa o lápis cor de pele", não há aí um simples nomear de uma tonalidade em uma paleta de cores. Ao identificar determinada cor como "a" cor da pele, significa legitimar que a cor 
da pele normal e dominante é aquela majoritariamente conhecida nos lápis, uma cor embranquecida. Dessa forma, é entendido que qualquer outra cor é diferente e que não deve ser utilizada, aprendendo assim a ser preconceituoso sem perceber. As crianças, normalmente, aceitam a cor rosa claro como a cor de pele, acham até visualmente bonito pintar os rostos, os braços e as pernas dessa cor. Infelizmente, acaba se tornando uma regra irrefletida nas escolas em geral. No livro há vários exemplos da Paula e suas amigas desenhando seus cabelos e pesquisando entre os lápis de cor, uma que represente, de forma real, suas peles, assim aprendendo a refletir sobre a diversidade étnica.

\subsection{QUESTÃO DE GÊNERO}

Nesta seção explano as questões acerca de gênero do livro As Bonecas Negras de Lara e suas devidas reflexões. As escolas no seu horizonte social precisam reconhecer identidades como construções plurais, considerando as individualidades de seus sujeitos, para, dessa forma, contribuírem para uma realidade com menor ou até mesmo sem discriminações por gênero. Sobre a distinção pejorativa criada historicamente entre os segmentos da sociedade, Jovchelovitch (1998) coloca que:

Tanto o sujeito negro como a mulher foram historicamente construídos por representações marcadas pela violência simbólica e por um conjunto de exclusões. Mas ambos (e certamente a mulher negra com mais esforço) lutaram, e lutam para não serem reduzidos a essas representações. Produzir contra representações, outras representações, que não reduzam a objetividade da condição negra e feminina às tentativas de lhe construir enquanto negatividade tem sido parte dos movimentos negros e do movimento de mulheres (JOVCHELOVITCH, 1998, p. 78).

Posso dizer, então, que a Lara é outra representação nesse horizonte social, pois é uma menina negra que coloca suas vontades e seus desejos a mostra. O livro traz o seu convívio com duas mulheres fortes: a tia-avó e a bisavó, que infiro tê-la influenciado em se tornar essa menina forte, que me faz pensar sobre uma história de luta dessas mulheres, que além de serem mulheres, são negras, e que possivelmente enfrentaram inúmeros desafios em suas trajetórias de vida. 
Por considerar crianças como sujeitos sociais capazes de múltiplas relações, tenho notado que novas relações de gênero têm se apresentado nas escolas, isto é, novas possibilidades de ser menina e novas possibilidades de ser menino. Ao enfocar as questões de gênero nos ambientes educativos é necessário, como afirma Louro (1997), que os sentidos estejam afiados para que sejamos capazes de ver, ouvir e sentir as múltiplas formas de constituição dos sujeitos implicadas na concepção, na organização e no fazer do cotidiano escolar, pois "Atentas aos pequenos indícios, veremos que até mesmo o tempo e o espaço da escola não são distribuídos e usados - portanto não são concebidos - do mesmo modo por todas as pessoas" (LOURO, 1997, p. 59).

Ao encontro dessas colocações, trago o personagem Sérgio, um menino negro que é amigo de Lara, e que ao passear no parque com seu pai leva seus brinquedos: carrinhos e bonecas, e lá encontra outras crianças, de forma em que tanto meninos quanto meninas brincam com os brinquedos que tem vontade, carrinho ou bonecas. Louro $(1997 ; 2000)$ afirma que a escola é parte importante neste processo. Seus estudos apontam para o modo como as instituições e suas práticas ensinam certas concepções, fazendo com que certas condutas e formas de comportamento, diferenciadas pelo sexo, sejam aprendidas e interiorizadas, tornando-se quase "naturais". Para a autora, tal 'naturalidade' tão fortemente construída "talvez nos impeça de notar que, no interior das atuais escolas, onde convivem meninos e meninas, rapazes e moças, eles e elas se movimentam, circulam e se agrupam de formas distintas" (LOURO, 1997, p. 56).

As relações das crianças na infância apresentam-se como forma de ingresso de meninos e meninas na vida social, quando passam a conhecer e aprender seus sistemas de regras e valores, pois interagem e participam nas construções sociais. Quando observo as relações entre as crianças, posso inferir que há estereótipos dos papéis prédefinidos, de comportamentos pré-determinados a meninas e a meninos. Os preconceitos e discriminações são construções culturais, que existem nas relações dos adultos, e por ainda não terem conseguido contaminar totalmente a cultura da criança, $o$ professor pode utilizar de sua análise e observação, para através da literatura mostrar o respeito que todos devem exercer com relação às diferenças de cada um, que são inerentes a todos os seres humanos, além de auxiliá-los a enxergar a multiplicidade de novos conhecimentos que essas diferenças podem trazer para a sala de aula, com relação à cultura de um modo geral, que cada etnia carrega consigo. 


\section{CONSIDERAÇÕES FINAIS}

No presente artigo desenvolvi algumas reflexões acerca da Teoria Racial Crítica, assim como as definiçõoes de seus constructos: Branquidade (Whiteness) e a ideologia de não ver a cor (colorblind) e tracei uma relação com o pensamento colonial que reflete, até hoje na sociedade brasileira, o racismo como uma das consequências. Em um segundo momento, trouxe a análise de um livro de literatura infantil com personagens negros (as) e sua importância para a desconstrução de estereótipos. Entretanto, não tive a intenção de estabelecer essas relações de maneira conclusiva no que foi abordado na pesquisa, visto que pretendi fomentar discussões acerca das questões raciais com intersecção em gênero dentro da Literatura Infantil.

Contudo, no que se refere aos objetivos da pesquisa, os quais permearam todo o texto, respondo a primeira pergunta citada nessa pesquisa: De que forma a Teoria Racial Crítica pode influenciar na área da educação? Com base nas reflexões teóricas enfatizo que a Teoria Racial Crítica pode tornar mais visível esses padrões culturais e raciais sistêmicos que operam nas escolas, oportunizando reflexões entre os professores sobre identidades raciais. Sendo assim, colabora com o desenvolvimento de ações efetivas para o combate e desconstrução do racismo institucional.

Com relação à segunda pergunta citada na pesquisa: Qual é a importância da Literatura Infantil para a realização de uma educação inclusiva que contemple a questão racial com intersecção em gênero? Fundamentada nas reflexões teóricas desenvolvidas no artigo, ressalto que embora a integração multiétnica e multicultural não seja produto exclusivo do trabalho escolar, a escola pode tornar-se um espaço privilegiado dessa integração, uma vez que nela coexiste grande número de referenciais culturais à disposição do aluno, entre eles os livros de Literatura Infantil com personagens negros e negras. É necessário, por exemplo, revisar escolhas de literatura infantil em linguagem não sexista e não racista; romper com os silenciamentos que permeiam todo o contexto pedagógico em torno das diferenças, problematizando-as.

Compreendo que é proeminente a importância da literatura infantil com personagens negros e negras, como instrumento de reflexão aos professores nas suas ressignificações das práticas docentes e aos alunos como representatividade negra e 
como a oportunidade de valorização da cultura africana e afro-brasileira. Sugiro ainda, um ambiente escolar com inclusão de bonecas e bonecos negros e a fomentação de pesquisas de biografias de autores negros e negras que, muitas vezes, permanecem esquecidos.

Há outras questões fundamentais para estudos futuros. Portanto, proponho outras pesquisas relacionadas à literatura infantil nos anos iniciais do ensino fundamental também em relação a identidades raciais, pois há uma lacuna a ser preenchida nessa faixa etária, porém interseccionada à classe, pois não podemos perder de vista o combate à desigualdade social, que é um problema que incomoda historicamente o povo brasileiro.

\section{REFERÊNCIAS BIBLIOGRÁFICAS}

APPLE, Michael. W. Consumindo o outro: branquidade, educação e batatas fritas baratas. In: COSTA, Marisa Vorraber e APPLE, Michael W. Escola Básica na virada do século. São Paulo: Cortez, 2002. pp. 25-43.

BRASIL. Ministério da Educação. Lei $n^{\circ} 10.639$, de 9 de janeiro de 2003. Altera a Lei $n^{\circ} 9.394$, de 20 de dezembro de 1996, que estabelece as diretrizes e bases da educação nacional, para incluir no currículo oficial da Rede de Ensino a obrigatoriedade da temática "História e Cultura Afro-Brasileira", e dá outras providências. Brasília, 2003. Disponível em: <https://www.planalto.gov.br/ccivil 03/leis/2003/110.639.htm>

CASTILLO, Suely Dulce de. A representação do negro na Literatura Brasileira: Novas Perspectivas. Revista Olhar de professor, v. 7, n. 1, pp. 103-113, 2004. Disponível em: <www.revista2.uepg.br/index.php/plhardeprofessor/article/view/1418/1063>. Acesso em: 15 abr. 2019.

CAVALLEIRO, Eliane dos Santos; GOMES, Jerusa Vieira. Do silêncio do lar ao silêncio escolar: racismo, preconceito e discriminação na educação infantil. São Paulo: Contexto, 1998.

EVARISTO, Conceição. Literatura Negra: uma poética de nossa afro-brasilidade. Revista Scripta, v. 13, n. 25, pp. 17-32, 2009, Belo Horizonte. Disponível em: <http://periodicos.pucminas.br/index.php/scripta/article/view/4365>. Acesso em: 15 abr. 2019.

FERREIRA, Aparecida de Jesus. Identidades sociais, letramento visual e letramento crítico: imagens na mídia acerca de raça/etnia. Trabalhos em Linguística Aplicada, v. 51, n. 1, pp. 195215, 2012, Campinas. Disponível em: <https://doi.org/10.1590/S0103-18132012000100010> . Acesso em: 17 abr. 2019.

FERREIRA, Aparecida de Jesus. Teoria Racial Crítica e Letramento Racial Crítico: narrativas e contranarrativas de identidade racial de professores de Línguas. Revista da Associação Brasileira de Pesquisadores/as Negros/as (ABPN), v. 6, n. 14, pp. 236-263, 2014. Disponível em: 〈http://abpnrevista.org.br/revista/index.php/revistaabpn1/article/view/141〉. Acesso em: 18 abr. 2019. 
FERREIRA, Aparecida de Jesus. As Políticas do Livro Didático e Identidades Sociais de Raças, Gênero, Sexualidade e Classe em Livros Didáticos. Campinas: Pontes Editores, 2014.

FERREIRA, Aparecida de Jesus. Narrativas Autobiográficas de Identidades Sociais de Raça, Gênero, Sexualidade e Classe em Estudos da Linguagem. Campinas: Pontes Editores, 2015.

FERREIRA, Susana Aparecida; FERREIRA Aparecida de Jesus. Identidades Sociais de Raça e Formação Continuada de Professores de Língua Inglesa. Educere et Educare, v. 10, n. 20, 2015. Disponível em: 〈https://e-revista.unioeste.br/index.php/educereeteducare/article/view/12612> Acesso em: 2 mai. 2019.

FREIRE, Paulo. Pedagogia do Oprimido. 38 ed. São Paulo: Paz e Terra, 2004.

GOMES, Nilma Lino. Trajetórias escolares, corpo negro e cabelo crespo: reprodução de estereótipos ou ressignificação cultural? Revista Brasileira de Educação, n. 21, set./out./dez. 2002. Disponível em: <www.scielo.br/pdf/rbedu/n21/n21a03.pdf> Acesso em 2 mai. 2019.

HALL, Stuart. Gênero, Sexualidade e Educação: uma perspectiva pós-estruturalista. Petrópolis: Vozes, 1997.

HALL, Stuart. Que “negro” é esse na cultura negra. Da diáspora, p. 335-349, 2003.

HALL, Stuart. A questão multicultural. Da diáspora: identidades e mediações culturais, p. 51100, 2003.

HALL, Stuart. Da diáspora: identidades e mediações culturais. Editora UFMG, 2006.

HARRIS, Violet J. African American Children's Literature. Freedom's Plow: Teaching in the Multicultural Classroom, p. 167, 1993. In: ALCARAZ, Rita de Cassia Moser; ALCARAZ, Marcelo Barbosa. A branquitude na literatura infantil: uma herança da colonialidade/Critical whiteness children in literature: a coloniality heritage. Revista Guavira Letras, Três Lagoas, v. 14, n. 28, pp. 360-370, set./dez. 2018.

JOVCHELOVITCH, Sandra. Re (des) cobrindo o outro: para um entendimento da alteridade na teoria das representações sociais. In: ARRUDA, Angela. (org.). Representando a alteridade. Petrópolis: Vozes, 1998.

KLEIN, Ana Maria; PASSOS, Luana; GALINDO, Mônica Abrantes. EDUCAÇÃO EM DIREITOS HUMANOS NA EDUCAÇÃO INFANTIL: TRABALHANDO COM CONTOS AFRICANOS. Nuances: estudos sobre Educação, v. 29, n. 3, pp. 55-67, set./dez. 2018. Disponível em: <revista.fct.unesp.br/index.php/Nuances/article/viewFile/4535/pdf> Acesso em: 2 mai. 2019.

LADSON-BILLINGS, Glória. Para além de uma educação multicultural: teoria racial crítica, pedagogia culturalmente relevante e formação docente. [set. 2001]. Entrevistadores: Luís Armando Gandin, Júlio Emílio Diniz-Pereira e Álvaro Moreira Hypolito: Universidade de Wisconsin (EUA), 2001. Entrevista concedida no gabinete da professora. Revista Educação e Sociedade, v. 23, n. 79, pp. 275-293, 2002. Disponível em: <www.scielo.br/pdf/es/v23n79/10858.pdf> Acesso em: 2 mai. 2019.

LOPES, Luiz Paulo da Moita. Por uma lingüística aplicada indisciplinar. Parábola, 2006. 
LOURO, Guacira Lopes. Currículo, gênero e sexualidade. Porto (Portugal): Porto Editora, 2000.

MOREIRA, Camila. Branquitude é Branquidade? Uma revisão teórica da Aplicação dos Termos no Cenário Brasileiro. Revista da ABPN, v. 6, n. 13, mar./jun.2014, pp. 73-87. Disponível em: $\langle$ http://abpnrevista.org.br/revista/index.php/revistaabpn1/article/download/151/148> Acesso em: 18 abr. 2019.

MÜLLER, Tânia M. P.; CARDOSO, Lourenço. Branquitude: estudos sobre a identidade branca no Brasil. Appris Editora e Livraria Eireli-ME, 2018.

PROENÇA FILHO, Domício. A trajetória do negro na literatura brasileira. Estudos avançados, v. 18, n. 50, pp. 161-193, 2004. Disponível em: 〈www.revistas.usp.br/eav/article/view/9980> Acesso em: 2 mai. 2019.

ROSEMBERG, Fúlvia. Literatura Infantil e Ideologia. V. 14. Global Editora. 1985.

SILVA, Petronilha Beatriz Gonçalves e. Educação das Relações Étnico-Raciais nas instituições escolares. Educar em Revista, v. 34, n. 69, pp. 193-207, 2018. Disponível em: $<$ www.scielo.br/scielo.php?script=sci_abstract\&pid=S0104-

40602018000300123\&Ing=pt\&nrm=iso>. Acesso em: 2 mai. 2019.

SILVA, Tomaz Tadeu da (org.). Identidade e diferença: a perspectivas dos estudos culturais. Petrópolis: Vozes, 2000.

STREET, Brian; BAGNO, Marcos. Perspectivas interculturais sobre o letramento. Filologia e linguística portuguesa, n. 8 , pp. 465-488, 2006. Disponível em: <www.revistas.usp.br/flp/article/view/59767>. Acesso em: 2 mai. 2019.

Recebido em: 05/12/2020

Aprovado em: 30/07/2021 